\title{
Incidence angle and gray-to-white-matter ratio dependence of the focused-ultrasound induced blood-brain barrier opening in non-human primates
}

Maria Eleni (Marilena) Karakatsani", Gesthimani Samiotaki, Matthew Downs, Elisa Konofagou

From Current and Future Applications of Focused Ultrasound 2014. 4th International Symposium Washington, D.C, USA. 12-16 October 2014

\section{Background/introduction}

FUS coupled with the systemic administration of microbubbles has been proved to open the Blood-Brain Barrier $(\mathrm{BBB})$ locally, transiently and non-invasively in nonhuman primates (NHP). However, the complexity of the NHP brain constitutes an obstacle in relating the volume size of the induced opening $(\mathrm{VBBB})$ to the geometric aspects of the method as well as the physiologic characteristics of the targeted areas. The objective of the current study is to quantify the correlation between the VBBB, the FUS pressure and the incidence angle. Additionally, the dependence of the opening shift on the



Figure 1 Overlay of the BBB opening onto a thresholded T1w image.

Columbia University, New York, New York, United States

(c) 2015 Karakatsani et al; licensee BioMed Central Ltd. This is an Open Access article distributed under the terms of the Creative 
gray-to-white-matter ratio at the targeted area is studied.

\section{Methods}

Five $(n=5)$ NHP, i.e., four macaques of the mulatta and one fascicularis, were sonicated in two brain structures, the caudate $(\mathrm{Cau})$ and putamen $(\mathrm{Pu})$ using FUS (F0: $500 \mathrm{kHz}$; PRF: 2Hz; duration 120s; PNP 300-600 kPa) while being intravenously administered with monodisperse (4-5 micron in diameter) microbubbles. The NHPs were scanned in a 3T MR scanner (Philips, USA) acquiring 3D $\mathrm{T} 1$ weighted $(\mathrm{T} 1 \mathrm{w})$ pre- and post-contrast images approximately 24 hours after BBB opening to allow for behavioral assessment in a separate study. The estimation of the incidence angle and the center of the targeted area was were by projecting the ultrasound beam propagation and the focal region onto the BBB opening site detected on postcontrast T1w images. To estimate the shift, an automated intensity-based algorithm was designed that identified the centroid of the actual opening and the VBBB. Finally, the opening was overlayed onto the brain region on a thresholded T1w image (figure) to quantify the percentage of gray matter (GM) and white matter (WM) affected from FUS.

\section{Results and conclusions}

VBBB increased from $106.79 \pm 50 \mathrm{~mm} 3$ to $305.7 \pm 50 \mathrm{~mm} 3$ at an incidence angle range of $73.67 \pm 0.19^{\circ}$ to $89.83 \pm$ $0.19^{\circ}$ at $300 \mathrm{kPa}$, respectively. Similar increase was obtained at other pressures suggesting a linear correlation between the three aforementioned components. The squared correlation coefficient (R2) varied from 0.71 to 0.97 when studying each NHP separately. The opening in the GM accounted for an average of $88.5 \pm 8.9 \%$ of the opening cases when targeting the $\mathrm{Pu}$, while $78.3 \pm 6.6 \%$ occurred in the GM when focusing on the Cau. In conclusion, the VBBB was found to strongly depend on both the incidence angle and the pressure applied. It was also concluded that the shift in the BBB opening region from the targeted one depends on the gray-to-white-matter ratio present in the focal region.

\section{Acknowledgements (Funding)}

The authors would like to thank Shih Ying Wu, Carlos Sierra Sanchez and Amanda Marie Buch for their contribution. This study was supported by the National Institutes of Health (AG038961 and EB009041), the Focused

Ultrasound Foundation and the W.H. Coulter Foundation.

Published: 30 June 2015

doi:10.1186/2050-5736-3-S1-P22

Cite this article as: Karakatsani et al.: Incidence angle and gray-to-whitematter ratio dependence of the focused-ultrasound induced blood-

brain barrier opening in non-human primates. Journal of Therapeutic

Ultrasound 2015 3(Suppl 1):P22.

\section{Submit your next manuscript to BioMed Central} and take full advantage of:

- Convenient online submission

- Thorough peer review

- No space constraints or color figure charges

- Immediate publication on acceptance

- Inclusion in PubMed, CAS, Scopus and Google Scholar

- Research which is freely available for redistribution

Submit your manuscript at www.biomedcentral.com/submit 